\title{
Effect of Acid Species on Cryptococcus sp. T1 and Construction of Its Bioreactor System for Continuous Neutralization of Acidic Media
}

\author{
Shintaro Nagaoka1,2, Yuko Kajiwara', Sayaka Toyama1, Masahiko Okai' ${ }^{1}$, Masami Ishida', \\ Naoto Urano ${ }^{*}$ (1) \\ ${ }^{1}$ Department of Ocean Science, Laboratory of Marine Biochemistry, Tokyo University of Marine Science and Technology, \\ Tokyo, Japan \\ ${ }^{2}$ Department of Life Science and Technology, Tokyo Institute of Technology, Yokohama, Japan \\ Email: *urano@kaiyodai.ac.jp
}

How to cite this paper: Nagaoka, S., Kajiwara, Y., Toyama, S., Okai, M., Ishida, M. and Urano, N. (2019) Effect of Acid Species on Cryptococcus sp. T1 and Construction of Its Bioreactor System for Continuous Neutralization of Acidic Media. Advances in Microbiology, 9, 74-86.

https://doi.org/10.4236/aim.2019.91006

Received: December 19, 2018

Accepted: January 13, 2019

Published: January 16, 2019

Copyright $\odot 2019$ by author(s) and Scientific Research Publishing Inc. This work is licensed under the Creative Commons Attribution International License (CC BY 4.0).

http://creativecommons.org/licenses/by/4.0/

(c) $\underset{\mathrm{EY}}{\mathrm{C}}$ Open Access

\begin{abstract}
Generally, the tolerance of yeasts to acid is stronger than that of bacteria. In addition, some of the yeasts are able to neutralize acidic media, which is called acid-neutralizing yeast. An acid-neutralizing yeast, Cryptococcus sp. strain T1, was previously isolated from Lake Tazawa in Japan. Here we investigated the effect of several types of acid on the neutralizing ability of strain $\mathrm{T} 1$, and we improved an existing bioreactor model to effectively neutralize acidic water. First we carried out a neutralizing test with strain T1 using casamino acid solution adjusted to $\mathrm{pH} 3.0$ - 5.0 with each inorganic or organic acid. The solutions adjusted to $\mathrm{pH} 3.0$ with nitric acid, phosphoric acid, sulfuric acid, and citric acid were neutralized by strain $\mathrm{T} 1$. The $\mathrm{pH} 3.0$ solutions with lactic acid, formic acid, and acetic acid were not neutralized. These results demonstrated that some types of organic acid avoid neutralization by strain T1, and we hypothesized that this might be due to the sterilizing function of non-dissociative organic acid. We then constructed a bioreactor system with a column filled with T1-immobilized alginate beads. The previous research identified a problem in this bioreactor system: the high level of ammonium ions $\left(\mathrm{NH}_{4}^{+}\right)$in the neutralized water might pollute water environments, and aluminum ions $\left(\mathrm{Al}^{3+}\right)$ included in acidic water prevent the neutralization. Here, we used zeolite to get rid of the $\mathrm{NH}_{4}^{+}$and $\mathrm{Al}^{3+}$, and the addition of a zeolite reactor enabled the bioreactor system to neutralize the acidic water with a decrease of $\mathrm{NH}_{4}^{+}$in the water.
\end{abstract}

\section{Keywords}

Acid-Tolerant Yeast, Acid-Neutralizing Yeast, Bioreactor, Organic Acid, 


\section{Introduction}

Lake Tazawa in Japan's Akita Prefecture is a caldera lake polluted with acidic water from upstream hot springs. Hydroelectricity project introduced acidic Tamagawa River water into Lake Tazawa in 1940, resulting in the lake's acidification. The acidification damaged the lake's surroundings and made the lake unsuitable for aquatic life. Although a plant was constructed at the Tamagawa River to neutralize acidic water and restore the $\mathrm{pH}$ value of Lake Tazawa, this did not succeed in complete neutralization.

In our recent study (Okai et al. 2017 [1]), we isolated the acid-tolerant yeast Cryptococcus sp. strain T1 from Lake Tazawa. Strain T1 was able to thrive in an extremely acidic medium (lower limit $\mathrm{pH} 2.0$ ), and it even exhibited the ability to neutralize the medium (lower limit $\mathrm{pH}$ 2.6). We also discovered the mechanism of neutralization by strain T1: the decomposing amino acids in the medium release ammonium ions $\left(\mathrm{NH}_{4}^{+}\right)$, and the $\mathrm{pH}$ value is thereby elevated.

Several research groups have reported that these types of yeast can thrive in acidic environments and that some of them show neutralizing ability. Pichia kudriavzevii strain NG7 is a yeast strain isolated from grape skins, and it is able to grow at $\mathrm{pH} 2.0$ [2]. Rhodotorula glutinis strain $\mathrm{R}-1$, isolated from Agatsuma River (the $\mathrm{pH}$ of which is 2.0 - 3.0) in Gunma prefecture, Japan, was reported to be capable of the neutralization of an acidic medium at $\mathrm{pH} 3.0$ within 15 days [3]. Our group also studied Candida fluviatilis strain CeA16, which demonstrated the ability to neutralize the acidic medium at $\mathrm{pH} 3.0$ after 1-day incubation [4]. Moreover, in an earlier study we isolated 12 species and 26 strains of acid-neutralizing yeasts from natural neutral water environments, thus establishing that acid-neutralizing yeasts live in not only acidic environments but also neutral environments [5]. Although there are some reports of the isolation and identification of acid-neutralizing yeasts, the detailed mechanisms of acid tolerance and neutralization have been unknown.

The addition of the chemical neutralizing agent calcium carbonate $\left(\mathrm{CaCO}_{3}\right)$ used at the Tamagawa River plant mentioned above is considered unsafe in terms of the environmental burden due to the surplus $\mathrm{CaCO}_{3}$. One of the promising solutions to this safety issue is the neutralizing bioremediation afforded by Cryptococcus sp. strain T1. In our Okai et al. (2017) study [1], we constructed a bioreactor with strain T1-immobilized alginate beads, and it succeeded in neutralizing the artificial acidic water. Drainage from Tamagawa River (approx. pH 3.6, added casamino acid as nutrition) was also neutralized. We observed that the aluminum ions $\left(\mathrm{Al}^{3+}\right)$ present in the drainage would obstruct the neutralization by strain T1. In addition, the neutralized water from the bioreactor contained a high concentration of $\mathrm{NH}_{4}^{+}$, which is considered harmful to some aq- 
uatic life.

We conducted the present study to investigate two matters. We first determined the effects of several types of acid on the ability of Cryptococcus sp. strain T1 to neutralize acid solutions. In the test of acid-neutralizing yeasts' neutralization ability performed in previous studies, only sulfuric acid solution was used [1] [2] [3] [4] [5]; the yeasts' response to other inorganic acids and organic solutions was not addressed. Our second research challenge was to improve the bioreactor we created in our earlier study. Here we used zeolite, which is a hydrate aluminosilicate mineral made from interlinked tetrahedra of alumina $\left(\mathrm{AlO}_{4}\right)$ and silica $\left(\mathrm{SiO}_{4}\right)$, in an attempt to improve the bioreactor.

\section{Materials and Methods}

\subsection{Medium Culture}

R2A liquid medium for the cultivation consisted of $0.1 \%$ yeast extract, $0.1 \%$ proteose peptone (Becton Dickinson, Franklin Lakes, NJ, USA), 0.1\% casamino acid (Nihon Pharmaceutical, Tokyo), 0.03\% $\mathrm{K}_{2} \mathrm{HPO}_{4}$ (Kokusan Chemicals, Tokyo), $0.1 \% \mathrm{D}$-(+)-glucose, $0.1 \%$ soluble starch, $0.06 \%$ sodium pyruvate, and $0.005 \% \mathrm{MgSO}_{4} \cdot 7 \mathrm{H}_{2} \mathrm{O}$ (Wako Chemicals, Osaka, Japan). Solid medium was made by adding $1.2 \%$ gellan gum (Kanto Chemical, Tokyo) to the liquid medium. The $\mathrm{pH}$ value was adjusted with sulfuric acid in ordinal studies, but with various types of acid in 2.2 .

\subsection{Neutralization Test}

The strain $\mathrm{T} 1$ was cultured at $25^{\circ} \mathrm{C}$ for $48 \mathrm{~h}$ with shaking in $30 \mathrm{~mL}$ of R2A liquid medium at $\mathrm{pH}$ 3.0. The cell pellet was obtained by centrifugation at $3000 \mathrm{rpm}$ and washed two times with $0.9 \%(\mathrm{w} / \mathrm{v})$ saline adjusted to $\mathrm{pH} 3.0$ with sulfuric acid. The washed pellet was added to $10 \mathrm{~mL}$ of $0.05 \%(\mathrm{w} / \mathrm{v})$ casamino acid solution and incubated at $25^{\circ} \mathrm{C}$ for $72 \mathrm{~h}$ with shaking. We prepared casamino acid solutions ranging from $\mathrm{pH} 3.0$ to $\mathrm{pH}$ 5.0, which were adjusted with each acid: nitric acid, phosphoric acid, sulfuric acid, acetic acid, citric acid, formic acid, lactic acid, or propionic acid. The $\mathrm{pH}$ value of each cultivate was measured every $24 \mathrm{~h}$.

\subsection{The Construction of the Bioreactor with Strain T1 Immobilized Beads}

The construction of a bioreactor was performed according to Okai et al. [1]. First, Cryptococcus sp. strain T1 was cultured in $1 \mathrm{~L}$ of R2A liquid medium (pH 3.6) at $25^{\circ} \mathrm{C}$ for $48 \mathrm{~h}$. The cultured cells were collected by centrifugation at 3000 $\mathrm{rpm}$, and the cell pellet thus obtained was suspended in a $0.9 \%$ saline (pH 3.6) and washed in it three times. After washing, we made a cell mixed suspension consisting of washed wet cells, $0.9 \%$ saline, and sodium alginate $(80-120 \mathrm{cP}$, Wako) at a ratio of 1:2:5 (w/v/v).

With the use of a syringe, the suspension was dropped into a $1 \%$ calcium 
chloride (Wako) solution to obtain T1-immobilized beads with a dia. of approx. $5 \mathrm{~mm}$. The obtained alginate beads were put into a jacketed column $(50 \mathrm{~cm}$ length $\times 1.5 \mathrm{~cm}$ dia., Bio-Rad, Hercules, CA). A peristaltic pump (MP-1000), fraction collector (CHF121SA, Advantec, Tokyo), and a thermostatic bath were connected via plastic tubes to the bioreactor column. The temperature of the column was maintained at $25^{\circ} \mathrm{C}$ by the thermostatic bath. Artificial acidic water (consisting of $0.05 \%(\mathrm{w} / \mathrm{v})$ casamino acid, acidified $\mathrm{pH} 3.6$ with sulfuric acid) was run through the column at $22 \mathrm{~mL} / \mathrm{h}$. Each $10 \mathrm{~mL}$ of eluate from the column was collected into a small tube of the fraction collector (CHF121SA, Advantec), and then both the $\mathrm{pH}$ value and the $\mathrm{NH}_{4}^{+}$concentration of these collected samples were measured. The $\mathrm{pH}$ values were measured by using LAQUA $\mathrm{pH}$ meter (F-72, Horiba, Kyoto, Japan), and the concentration of $\mathrm{NH}_{4}^{+}$was measured by the enzymatic method with F-kit ammonium (JK International, Tokyo).

\subsection{Neutralization Test by the Bioreactor with Zeolite Reactor}

Three columns were prepared: 1 ) a $15 \mathrm{~cm}$ long $\times 1.5 \mathrm{~cm}$ dia. column (Bio-Rad) filled with $15 \mathrm{~g}$ zeolite, 2) a $10 \mathrm{~cm}$ long $\times 1.5 \mathrm{~cm}$ dia. column (Bio-Rad) filled with $16 \mathrm{~g}$ zeolite, and 3) a $10 \mathrm{~cm}$ long $\times 2.5 \mathrm{~cm}$ dia. column (Bio-Rad) filled with $45 \mathrm{~g}$ zeolite. The zeolite stones (Tosoh Co., Tokyo) were well washed with distilled water before being placed in the columns. A single zeolite reactor was connected between the bioreactor column and the fraction collector via plastic tubing. The column with $15 \mathrm{~g}$ of zeolite was connected downstream of the bioreactor for the elimination of excessive amounts of $\mathrm{NH}_{4}^{+}$. In contrast, the column with $16 \mathrm{~g}$ or $45 \mathrm{~g}$ of zeolite was set upstream of the bioreactor for an $\mathrm{Al}^{3+}$-decrease test. In addition to this test, we used acidic water consisting of $0.05 \%$ casamino acid (w/v) and $100 \mathrm{ppm}$ of aluminum sulfates (Wako), adjusted to $\mathrm{pH} 3.6$ by sulfuric acid. The scheme of the bioreactor system is shown in Figure 1.

The temperature and flow rate were set to the same as those without the zeolite reactors. The $\mathrm{pH}$ value of the eluates collected in fractions was measured. In the $\mathrm{NH}_{4}^{+}$elimination test, the concentration of the ammonium ions was also measured.

\section{Results}

\subsection{Neutralization of Artificial Acidic Media by Acid-Neutralizing Yeast}

We first carried out a neutralizing test with artificial acidic media, adjusted to $\mathrm{pH} 3.0$ by an inorganic acid (nitric acid, phosphoric acid, or sulfuric acid) or to pH 3.0 - 5.0 by an organic acid (acetic acid, citric acid, formic acid, lactic acid, or propionic acid). As shown in Figure 2, all of the media acidified with an inorganic acid were neutralized by strain $\mathrm{T} 1$. The $\mathrm{pH}$ value of all three media rose up to approx. 7.0 on day 1 . On day 3 , the $\mathrm{pH}$ value was 7.7 when nitric acid was used, 6.9 when phosphoric acid was used, and 7.6 when sulfuric acid was used. 


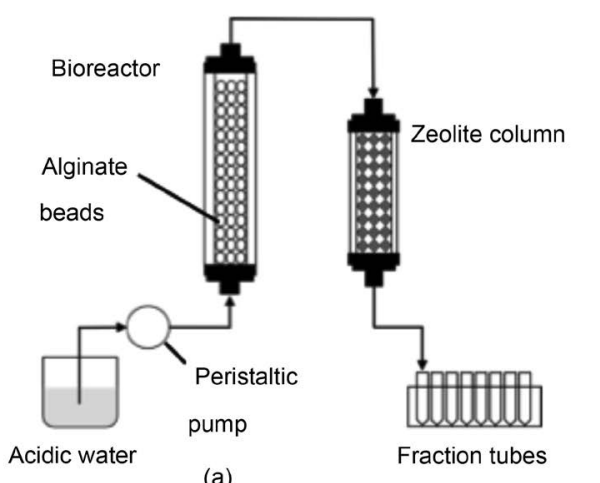

(a)

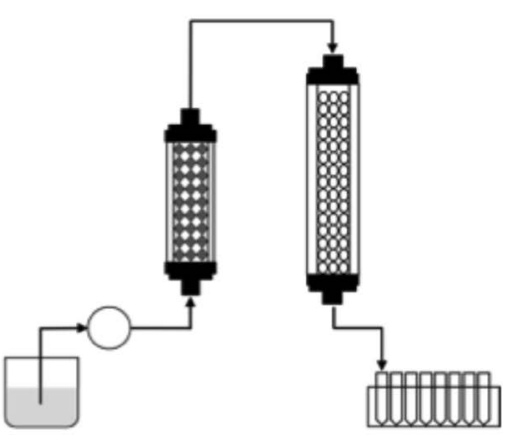

(b)

Figure 1. Scheme of the bioreactor with Cryptococcus sp. strain T1 immobilized alginate beads and the zeolite reactor. (a) A system for the ammonium elimination test. Acidic water was led into the bioreactor column by aperistaltic pump, and after passing through the column, the water was run through the zeolite reactor and finally collected into fraction tubes. (b) For the aluminum elimination test, a zeolite reactor was upstream of the bioreactor and acidic water was run first through the zeolite reactor. In the test without azeolite reactor, the eluate passed through only the bioreactor and was then collected directly into the tubes.

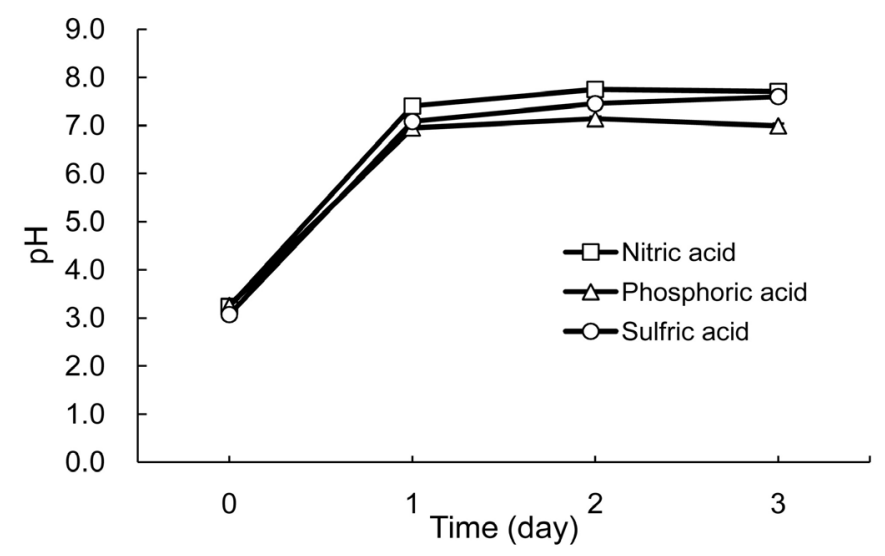

Figure 2. The neutralization of artificial acidic water by Cryptococcus sp. strain $\mathrm{T} 1$. The initial $\mathrm{pH}$ of the water was adjusted to $\mathrm{pH}$ 3.0 with each inorganic acid: sulfuric acid, nitric acid, and phosphoric acid. Strain T1 was cultivated in the water for 3 days at $25^{\circ} \mathrm{C}$, and the supernatant obtained by centrifugation at $3000 \mathrm{rpm}$ was collected to measure the $\mathrm{pH}$ value every day. Data are from triple independent measurements.

Regarding the media with organic acid, the trend of neutralization differed among the types of acid (Figure 3), as follows. Acetic acid: The media at pH 4.5 and 4.0 were neutralized in 3 days, whereas the $\mathrm{pH}$ value did not change at 3.5 or 3.0. Citric acid: The $\mathrm{pH}$ value of all media at $\mathrm{pH} 4.0,3.5$, and 3.0 were neutralized within 3 days. Formic acid: Only the $\mathrm{pH} 4.0$ medium was neutralized in 3 days; the media at $\mathrm{pH} 3.5$ and 3.0 showed no change. Lactic acid: $\mathrm{pH} 4.0$ and 3.5 media were neutralized, but the $\mathrm{pH}$ value of $\mathrm{pH} 3.0$ medium did not rise. Propionic acid: The $\mathrm{pH} 5.0$ and 4.5 media were neutralized within 3 days, but the pH 4.0 and 3.0 media did not change. 

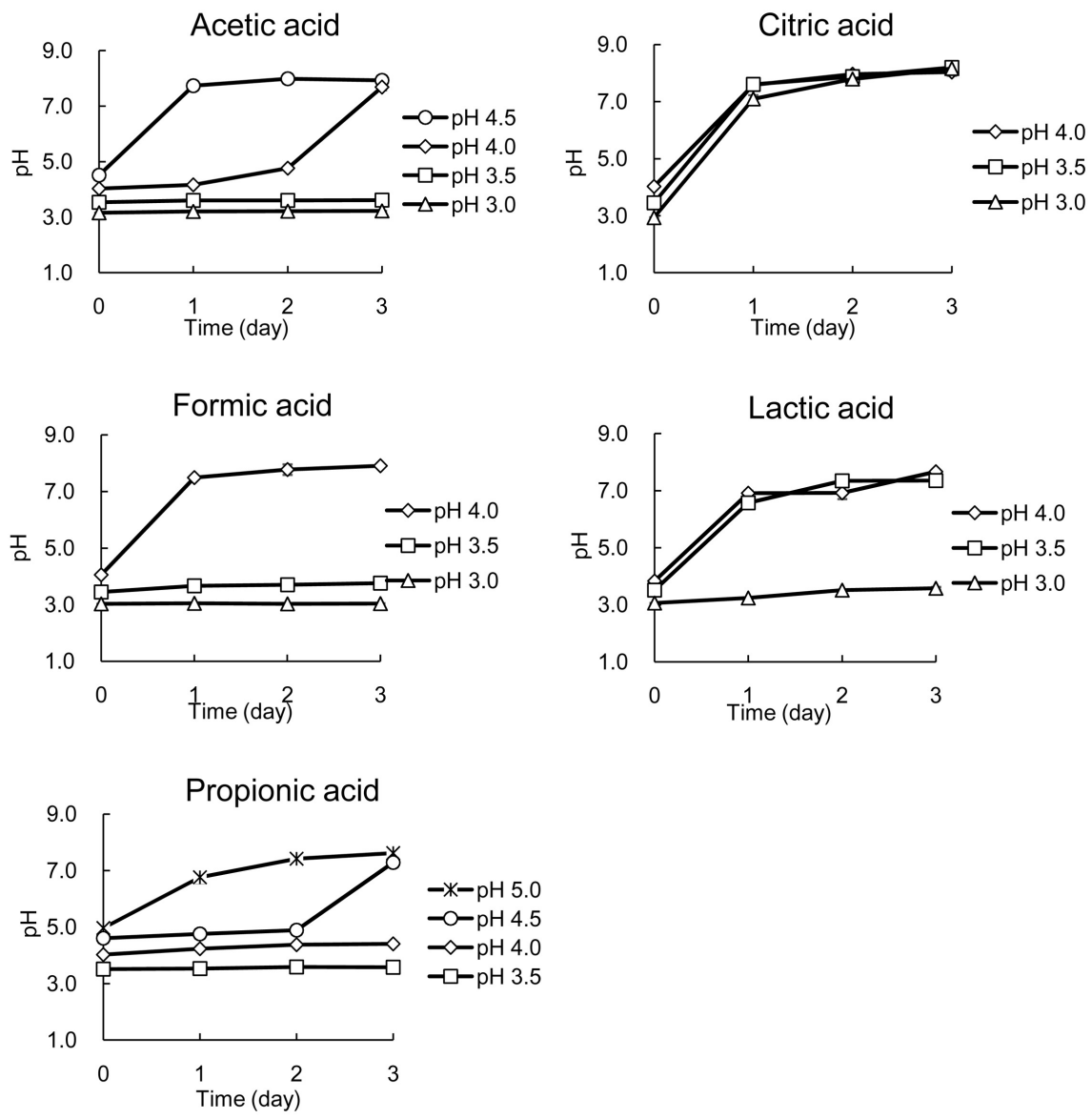

Figure 3. The $\mathrm{pH}$ changes of the artificial acidic water in which Cryptococcus sp. strain T1 was cultivated. The water adjusted to $\mathrm{pH} 3.5$ - 5.0 with each organic acid, and the cultivation was carried out for 3 days at $25^{\circ} \mathrm{C}$. The $\mathrm{pH}$ value of the supernatant was measured every day after centrifugation at $3000 \mathrm{rpm}$. The results are the average of three independent experiments with the SDs.

\subsection{The Artificial Acidic Water Neutralization by Strain T1 Immobilized the Bioreactor against Prevention with Aluminum Ions}

The results of the neutralization test by the bioreactor with or without the zeolite reactor are illustrated in Figure 4. In the test without zeolite reactor, the $\mathrm{pH}$ value of the eluate first collected in fraction tubes was 6.74 , and that of the last tube was 6.62. The average value of all fractions was 6.58. In the test with the zeolite, the first tube showed the $\mathrm{pH}$ value of 6.74 , and the last one was 7.04 ; the average was 6.97 .

We used an enzymatic method to measure the amount of $\mathrm{NH}_{4}^{+}$. Figure 5 shows the changes in the concentration of $\mathrm{NH}_{4}^{+}$in the collected eluate. In the test without zeolite, the concentration of $\mathrm{NH}_{4}^{+}$increased sharply, and the maximum value was $9.09 \times 10^{-3} \mathrm{~g} / \mathrm{L}$. In the test with zeolite, $\mathrm{NH}_{4}^{+}$was not detected until the flow volume of $220 \mathrm{~mL}$, and after that its level increased gently to $5.53 \times 10^{-3} \mathrm{~g} / \mathrm{L}$ as the maximum value. The average $\mathrm{NH}_{4}^{+}$concentration without zeolite was $5.90 \times 10^{-3} \mathrm{~g} / \mathrm{L}$, and the average with zeolite was $2.04 \times 10^{-3} \mathrm{~g} / \mathrm{L}$. 


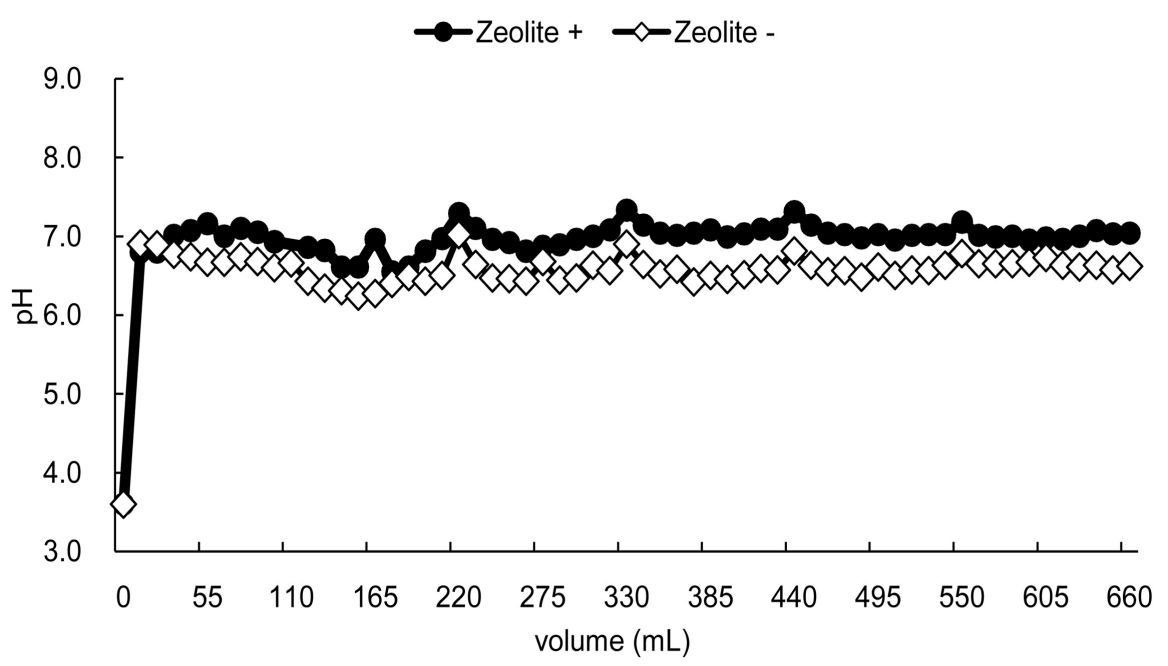

Figure 4. Neutralization of artificial acidic water using the bioreactor and zeolite reactor. The water passed through the bioreactor was collected into fraction tubes, and then the $\mathrm{pH}$ value was measured directly. Black dots $(\bullet)$ represent the $\mathrm{pH}$ change of the eluate in the test with a zeolite reactor, and the white rhombuses $(\diamond)$ represent the changes without a zeolite reactor.

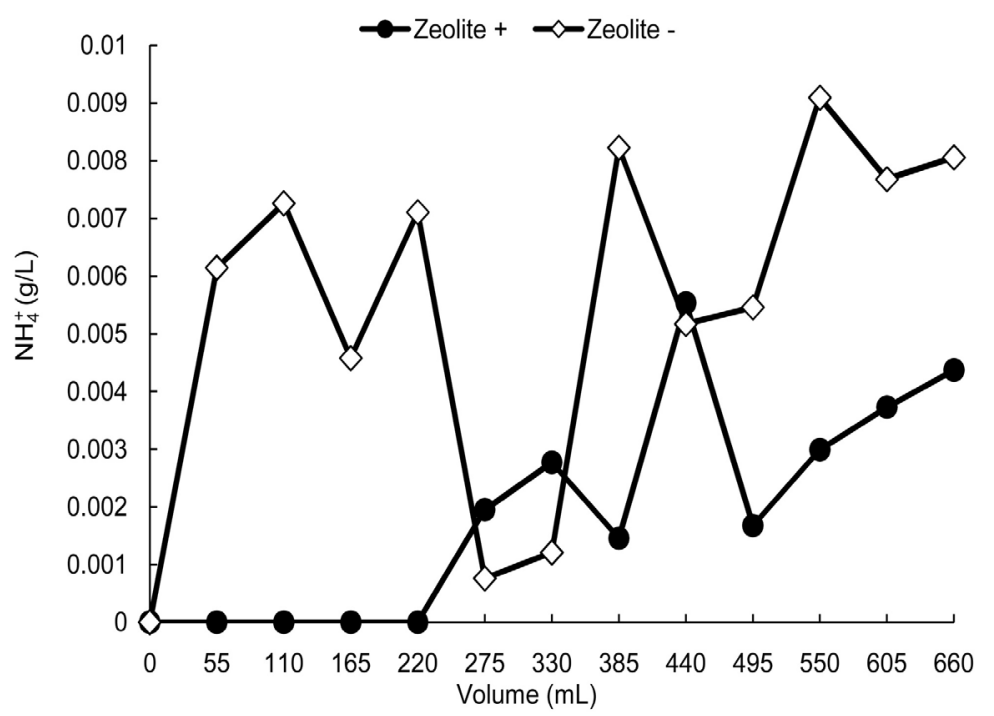

Figure 5. The changes in the ammonium ion concentration of the eluate from the bioreactor with strain T1 immobilized alginate beads. After approx. $5.5 \mathrm{~mL}$ of the eluate was collected into a fraction tube, a portion of the eluate was used for the subsequent ammonium ion assay. The dots $(\bullet)$ represent the ammonium ion concentration of the eluate obtained in the test with a zeolite reactor, and the rhombuses $(\diamond)$ are the result of the test without a zeolite reactor.

The results of the neutralization tests using the bioreactor with a zeolite reactor against aluminum ions are shown in Figure 6. The white plots present the $\mathrm{pH}$ value change in the tests without a zeolite reactor. The first neutralized fraction's $\mathrm{pH}$ value was 6.05 , and the $\mathrm{pH}$ began to decrease starting with the next tube. The last tube's $\mathrm{pH}$ value was 3.29. When a column with $16 \mathrm{~g}$ of zeolite was 


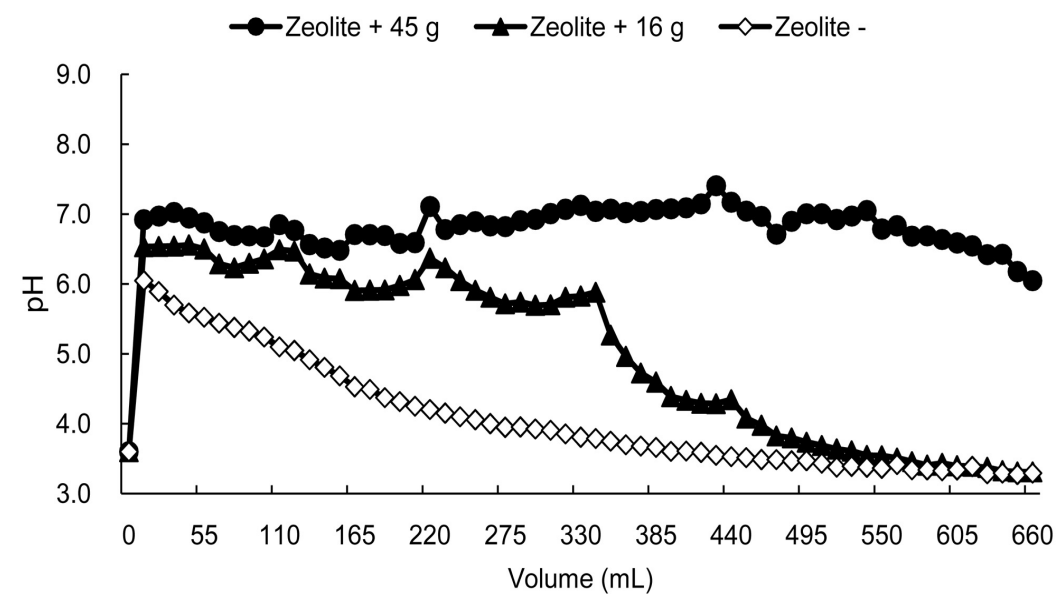

Figure 6. Neutralization test by the bioreactor with a zeolite reactor against aluminum ions. Using artificial acidic water ( $\mathrm{pH} 3.6)$ containing $100 \mathrm{ppm}$ aluminum sulfate, the neutralization by the bioreactor with a zeolite reactor was tested. Here, $45 \mathrm{~g}$ and $16 \mathrm{~g}$ of zeolite had been packed into a column and set upstream of the bioreactor column.

used, the acidic water was neutralized (the first tube's $\mathrm{pH}$ was 6.53) until the flow volume of $340 \mathrm{~mL}$, but the $\mathrm{pH}$ decreased to $\mathrm{pH} 3.31$ at the last tube. With the $45 \mathrm{~g}$ of zeolite, the first tube showed $\mathrm{pH} 6.92$, and the value remained stable at around 7.0. Although the $\mathrm{pH}$ decreased after the flow volume of $440 \mathrm{~mL}$, the final $\mathrm{pH}$ stayed over $\mathrm{pH}$ 6.0. The average $\mathrm{pH}$ values were as follows. Without zeolite: 4.07; with $16 \mathrm{~g}$ of zeolite: 5.01; with $45 \mathrm{~g}$ of zeolite: 6.77 .

\section{Discussion}

Our results demonstrated that Cryptococcus sp. strain T1 could neutralize media at pH 3.0 acidified with inorganic acids, i.e. sulfuric acid, nitric acid, and phosphoric acid. The trends of neutralization were almost the same among these three acids; it appeared that these three acids do not prevent the neutralizing ability of strain T1. Our test using organic acids showed results that differed from those of the tests using inorganic acids. Strain T1 neutralized media acidified with acetic acid to $\mathrm{pH} 4.0$ and 4.5, but the strain could not neutralize $\mathrm{pH} 3.0$ or 3.5 media. Except for the citric acid (all media were neutralized within 1 day), the cases of the other organic acids were similar to this result: the lower the initial $\mathrm{pH}$ value was, the weaker the neutralizing ability of strain $\mathrm{T} 1$ became. We speculate that this tendency depends on a sterilization effect which organic acids possess. As some researchers have indicated [6]-[11], some organic acids show the ability to decrease the activities of microorganisms.

Organic acid exists as two different forms in a solvent; one is a dissociated molecule which has released its protons, and the other is a non-dissociated molecule. These two forms coexist and maintain a state of equilibrium, and the ratio of the two forms of the molecule depends on the pKa value of each acid. Some of the non-dissociated molecules are able to permeate through the cell membrane [6] [7] [8]; these dissociate inside the cell and acidify and damage the intercellu- 
lar region, decreasing the activities of the microorganisms. Low $\mathrm{pH}$ values increase the ratio of non-dissociated organic acid.

Strain T1 might be affected by the sterilization effect. Its neutralizing ability was inactivated in the water with $\mathrm{pH}$ value $\leq 3.5$. However, $\mathrm{pH} 3.0$ and 3.5 citric acid solution was neutralized within 1 day. The $\mathrm{pKa}$ value may be associated with the results; the pKa value of citric acid is 2.79 [12], the lowest value among all of the organic acids used in this test. Most citric acid molecules exist as the dissociated form in water of $\geq \mathrm{pH} 3.0$, and thus citric acid's sterilization effect might have been weaker than the others.

Okai et al. [1] showed that Cryptococcus sp. strain T1 neutralizes acidic water by decomposing amino acids into $\mathrm{NH}_{4}^{+}$. Therefore, the eluate through the bioreactor could contain a considerable concentration of $\mathrm{NH}_{4}^{+}$, which is thought to be harmful [13] [14] [15] [16] [17] to some animals. In addition, a high concentration of $\mathrm{Al}^{3+}$ in an acidic environment is thought to prevent the neutralizing ability of strain T1. Several studies showed that zeolite stones are able to eliminate some cations in water [18] [19] [20] [21] such as calcium ions, magnesium ions, and even ammonium ions [22] [23] [24]. We thus conducted tests using a zeolite reactor in the present study in order to eliminate $\mathrm{NH}_{4}^{+}$and $\mathrm{Al}^{3+}$ as part of our efforts to improve our bioreactor.

Figure 4 shows that the artificial acidic water was neutralized after passing through the bioreactor column. The $\mathrm{pH}$ values of the eluates stayed at around 7.0 for the last fraction tube, indicating that strain $\mathrm{T} 1$ immobilized-alginate beads neutralized the water. Figure 5 presents the concentration of $\mathrm{NH}_{4}^{+}$in the eluate. In the test without a zeolite reactor, the concentration increased rapidly and the average values were high $\left(5.90 \times 10^{-3} \mathrm{~g} / \mathrm{L}\right.$, as noted $)$. On the other hand, with the use of a zeolite reactor the concentration did not increase quickly but rose gently after the flow volume of $220 \mathrm{~mL}$, and the average values was low $(2.04 \times$ $10^{-3} \mathrm{~g} / \mathrm{L}$ ); it was thus revealed that the zeolite reactor eliminated $65.4 \%$ of the $\mathrm{NH}_{4}^{+}$.

However, in light of our observation that the $\mathrm{NH}_{4}{ }^{+}$concentration increased late in the tests with zeolite, we speculated that the possibility of the elimination of $\mathrm{NH}_{4}^{+}$might be limited. We suspect that from the start of the bioreactor reactions to the flow volume of $220 \mathrm{~mL}$, the amount of $\mathrm{NH}_{4}^{+}$ions eliminated might be within the capacity, but after $220 \mathrm{~mL}$ the amount of $\mathrm{NH}_{4}^{+}$exceeded the capacity, and the zeolite was therefore not able to decrease the $\mathrm{NH}_{4}^{+}$, and its concentration increased.

Some prior research has described the mechanism of $\mathrm{NH}_{4}^{+}$elimination by zeolite stones. Briefly, zeolite is a porous material, and the $\mathrm{NH}_{4}^{+}$is absorbed in zeolite via an ion exchange with cations in the molecules composing the zeolite. It thus might be possible to restore the absorbing ability of zeolite by washing away the absorbed $\mathrm{NH}_{4}^{+}$, via another ion exchange. More simply, when using a larger column and much more zeolite stones, the amount of $\mathrm{NH}_{4}^{+}$removed would increase. 
As shown in Figure 6, the bioreactor system with an upstream zeolite reactor successfully neutralized the acidic water with a high concentration of $\mathrm{Al}^{3+}$. The larger amount of zeolite used, the higher $\mathrm{pH}$ values the eluates showed. In contrast, in the test without a zeolite reactor, the eluate initially showed high $\mathrm{pH}$ values, but the $\mathrm{pH}$ then decreased. These results indicate that zeolite might make a contribution to the neutralization by strain $\mathrm{T} 1$, and that this contribution could be caused by the cation exchange by the zeolite.

As noted above in the discussion of the $\mathrm{NH}_{4}^{+}$elimination test, zeolite stones are able to exchange cations. Several groups [18] [19] [20] [21] have reported that this cation exchange could also apply to the metal ions, in this case $\mathrm{Al}^{3+}$. In the present study's neutralization test without azeolite reactor, the $\mathrm{Al}^{3+}$ present in the artificial acidic water might have influenced the neutralizing ability of strain $\mathrm{T} 1$, and thus the $\mathrm{pH}$ soon decreased. This theory is consistent with the results of our tests with zeolite. We observed that with $16 \mathrm{~g}$ of zeolite, the neutral $\mathrm{pH}$ value was maintained upto the flow volume of $340 \mathrm{~mL}$, which is a decreasing point, and $45 \mathrm{~g}$ of zeolite postponed the decreasing point to the flow volume 440 $\mathrm{mL}$. We thus speculate that the greater the amount of zeolite used, the later the decreasing point will appear.

This study is a first investigation of the neutralizing ability of Cryptococcus sp. T1 applied to organic acid solutions. Not only strain T1 but also other acid-neutralizing yeasts have been isolated from acidic environments with inorganic acids, and it was reported that these yeasts neutralize an inorganic acid solution [1] [2] [3] [4] [5]. The effect of organic acids on these yeasts had been unknown. Herein we succeeded in our efforts to improve the existing bioreactor; the $\mathrm{NH}_{4}^{+}$in the eluates was eliminated or decreased by the zeolite reactor attached downstream, and an upstream zeolite reactor enabled the neutralization of acidic water (including $\mathrm{Al}^{3+}$ ) by the reactor.

The most widespread method used to neutralize water polluted by acids is the addition of a chemical-neutralizing agent, but this is considered unsafe for natural environments. Methods that use microorganisms are a good approach, and thus a greater understanding of acid-neutralizing yeasts and further improvements of bioreactors are necessary.

\section{Conclusions}

The acid-neutralizing yeast Cryptococcus sp. strain T1 neutralized artificial water that had been acidified with an inorganic or organic acid: sulfuric acid, nitric acid, and phosphoric acid, and acetic acid, citric acid, formic acid, lactic acid, or propionic acid. Some of the organic acid solutions ( $\mathrm{pH}$ value $\leq 3.5$ ) prevented strain T1 from neutralizing due to the sterilization effect of organic acids.

The existing bioreactor with strain T1-immobilized alginate beads was improved. With the attachment of a column filled with zeolite stones (which are known as a cation-removing agent) downstream of the bioreactor, approx. $65.4 \%$ of the $\mathrm{NH}_{4}^{+}$in eluate was eliminated compared to the result of without 
zeolite. In addition, with a zeolite reactor attached with upstream of the bioreactor, the bioreactor was able to neutralize acidic water that had a high concentration of $\mathrm{Al}^{3+}$.

\section{Acknowledgements}

This work was supported in part by a Japan Society for the Promotion of Science KAKENHI Grant-in-Aid for Scientific Research (grant No. 16K07868).

\section{Conflicts of Interest}

The authors declare no conflicts of interest regarding the publication of this paper.

\section{References}

[1] Okai, M., Suwa, C., Nagaoka, S., Obara, N., Mitsuya, D., Kurihara, A., Ishida, M. and Urano, N. (2017) Neutralization of Acidic Drainage by Cryptococcus sp. T1 Immobilized in Alginate Beads. Bioscience Biotechnology and Biochemistry, 81, 2216-2224. https://doi.org/10.1080/09168451.2017.1373586

[2] Park, H.J., Bae, J.H., Ko, H.J., Lee, S.H., Sung, B.H., Han, J.I. and Sohn, J.H. (2018) Low-pH Production of D-Lactic Acid Using Newly Isolated Acid Tolerant Yeast Pichia kudriavzevii NG7. Biotechnology and Bioengineering, 115, 2232-2242. https://doi.org/10.1002/bit.26745

[3] Nguyen, V.A.T., Senoo, K., Mishima, T. and Hisamatsu, M. (2001) Multiple Tolerance of Rhodotorula glutinis R-1 to Acid, Aluminum Ion and Manganese Ion, and Its Unusual Ability of Neutralizing Acidic Medium. Journal of Bioscience and Bioengineering, 92, 366-371. https://doi.org/10.1016/S1389-1723(01)80241-3

[4] Mitsuya, D., Hayashi, T., Wang, Y., Tanaka, M., Okai, M., Ishida, M. and Urano, N. (2017) Isolation of Aquatic Yeasts with the Ability to Neutralize Acidic Media, from an Extremely Acidic River near Japan's Kusatsu-Shirane Volcano. Journal of Bioscience and Bioengineering, 124, 43-46. https://doi.org/10.1016/j.jbiosc.2017.02.005

[5] Nagaoka S., Kobayashi T., Kajiwara Y., Okai M., Ishida M. and Urano N. (2017) Characterization of Yeasts Capable of Neutralizing Acidic Media from Natural Neutral Environments. Advances in Microbiology, 7, 887-897.

https://doi.org/10.4236/aim.2017.712068

[6] Walter A. and Gutknecht J. (1984) Monocarboxylic Acid Permeation through Lipid Bilayer Membranes. The Journal of Membrane Biology, 77, 255-264.

https://doi.org/10.1007/BF01870573

[7] Poole, R.C. and Halestrap, A.P. (1993) Transport of Lactate and Other Monocarboxylates across Mammalian Plasma Membranes. American Journal of Physiology-Cell Physiology, 264, C761-C782. https://doi.org/10.1152/ajpcell.1993.264.4.C761

[8] Narendranath, N.V., Thomas, K.C. and Ingledew, W.M. (2001) Effects of Acetic Acid and Lactic Acid on the Growth of Saccharomyces cerevisiae in a Minimal Medium. Journal of Industrial Microbiology and Biotechnology, 26, 171-177. https://doi.org/10.1038/sj.jim.7000090

[9] Ludovico, P., Sousa, M.J., Silva, M.T., Leão, C. and Côrte-Real, M. (2001) Saccharomyces cerevisiae Commits to a Programmed Cell Death Process in Response to Acetic Acid. Microbiology, 147, 2409-2415. 
https://doi.org/10.1099/00221287-147-9-2409

[10] Warnecke, T. and Gill, R.T. (2005) Organic Acid Toxicity, Tolerance, and Production in Escherichia coli Biorefining Applications. Microbial Cell Factories, 4, 25. https://doi.org/10.1186/1475-2859-4-25

[11] Mollapour, M. and Piper, P.W. (2007) Hog1 Mitogen-Activated Protein Kinase Phosphorylation Targets the yeast Fps1 Aquaglyceroporin for Endocytosis, Thereby Rendering Cells Resistant to Acetic Acid. Molecular and Cellular Biology, 27, 6446-6456. https://doi.org/10.1128/MCB.02205-06

[12] Serjeant, E.P. and Dempsey, B. (1979) Ionisation Constants of Organic Acids in Aqueous Solution. Pergamon Press, New York.

[13] Erickson, R.J. (1985) An Evaluation of Mathematical Models for the Effects of pH and Temperature on Ammonia Toxicity to Aquatic Organisms. Water Research, 19, 1047-1058. https://doi.org/10.1016/0043-1354(85)90375-6

[14] Schubaur-Berigan, M.K., Monson, P.D., West, C.W. and Ankley, G.T. (1995) Influence of $\mathrm{pH}$ on the Toxicity of Ammonia to Chironomus tentans and Lumbriculus variegatus. Environmental Toxicology and Chemistry, 14, 713-717. https://doi.org/10.1002/etc.5620140419

[15] Randall, D.J. and Tsui, T.K. (2002) Ammonia Toxicity in Fish. Marine Pollution Bulletin, 45, 17-23. https://doi.org/10.1016/S0025-326X(02)00227-8

[16] Sinha, A.K., Liew, H.J., Diricx, M., Blust, R. and De Boeck, G. (2012) The Interactive Effects of Ammonia Exposure, Nutritional Status and Exercise on Metabolic and Physiological Responses in Gold Fish (Carassius auratus L.). Aquatic Toxicology, 109, 33-46. https://doi.org/10.1016/j.aquatox.2011.11.002

[17] Lu, Q., Chen, P., Addy, M., Zhang, R., Deng, X., Ma, Y., Cheng, Y., Hussain, F., Chen, C., Liu, Y. and Ruan, R. (2018) Carbon-Dependent Alleviation of Ammonia Toxicity for Algae Cultivation and Associated Mechanisms Exploration. Bioresource Technology, 249, 99-107. https://doi.org/10.1016/j.biortech.2017.09.175

[18] Ming, D.W. and Dixon, J.B. (1987) Quantitative Determination of Clinoptilolite in Soils by a Cation-Exchange Capacity Method. Clays and Clay Minerals, 35, 463-468. https://doi.org/10.1346/CCMN.1987.0350607

[19] Roberto, T.P. and Bertetti, F.P. (2001) Cation-Exchange Properties of Natural Zeolites. Reviews in Mineralogy and Geochemistry, 45, 453-518. https://doi.org/10.2138/rmg.2001.45.14

[20] Erdem, E., Karapinar, N. and Donat, R. (2004) The Removal of Heavy Metal Cations by Natural Zeolites. Journal of Colloid and Interface Science, 280, 309-314. https://doi.org/10.1016/j.jcis.2004.08.028

[21] Shaheen, S.M., Derbalah, A.S. and Moghanm, F.S. (2012) Removal of Heavy Metals from Aqueous Solution by Zeolite in Competitive Sorption System. International Journal of Environmental Science and Development, 3, 362-367. https://doi.org/10.7763/IJESD.2012.V3.248

[22] Ngeyen, M.L. and Tanner, C.C. (1998) Ammonium Removal from Wastewaters Using Natural New Zealand Zeolites. New Zealand Journal of Agricultural Research, 41, 427-446. https://doi.org/10.1080/00288233.1998.9513328

[23] Cooney, E.L., Booker, N.A., Shallcross, D.C. and Stevens, G.W. (1999) Ammonia Removal from Wastewaters Using Natural Australian Zeolite. II. Pilot-Scale Study Using Continuous Packed Column Process. Separation Science and Technology, 34, 2741-2760. https://doi.org/10.1081/SS-100100802

[24] Vitzthum von Eckstaedt, S., Charles, W., Ho, G. and Cord-Ruwisch, R. (2016) Nov- 
el Process of Bio-Chemical Ammonia Removal from Air Streams Using a Water Reflux System and Zeolite as Filter Media. Chemosphere, 144, 257-263.

https://doi.org/10.1016/j.chemosphere.2015.08.048 